
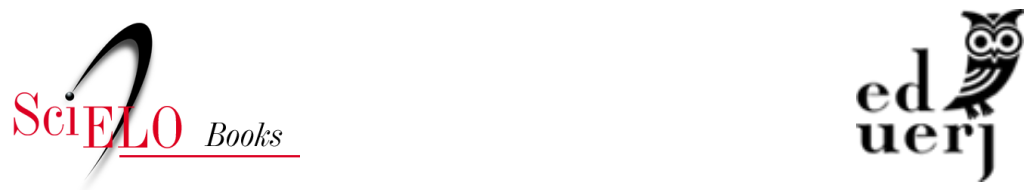

\title{
Ensino superior em Caruaru-PE uma cidade de responsabilidade territorial?
}

\author{
Mariana Rabêlo Valença
}

\section{SciELO Books / SciELO Livros / SciELO Libros}

VALENÇA, M. R. Ensino superior em Caruaru-PE: uma cidade de responsa bilidade territorial? In: MAIA, D. S., and MARAFON, G. J., eds. Ensino superior e desenvolvimento regional: reconfigurando as relações entre as cidades e o campo [online]. Rio de Janeiro: EDUERJ, 2020, pp. 47-80. ISBN: 978-65-87949-08-6. https://doi.org/10.7476/9786587949086.0003.

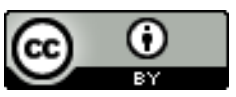

All the contents of this work, except where otherwise noted, is licensed under a Creative Commons Attribution 4.0 International license.

Todo o conteúdo deste trabalho, exceto quando houver ressalva, é publicado sob a licença Creative Commons Atribição 4.0.

Todo el contenido de esta obra, excepto donde se indique lo contrario, está bajo licencia de la licencia Creative Commons Reconocimento 4.0. 


\section{ENSINO SUPERIOR EM CARUARU-PE: UMA CIDADE DE RESPONSABILIDADE TERRITORIAL?}

Mariana Rabêlo Valença

\section{Introdução}

No contexto da globalização, novas centralidades vão se constituindo no movimento da urbanização brasileira. As cidades médias inserem-se nesse movimento e devem ser pensadas por seus papéis e funções na rede urbana, resultantes da articulação cada vez mais complexa de escalas geográficas, que alteram os padrões da estruturação e reforçam sua centralidade e intermediação por meio das novas relações que se estabelecem.

Tomamos como dimensão empírica Caruaru, no Agreste pernambucano, com a maior população fora de Região Metropolitana do Recife - RMR. As atividades que a capital do Agreste desempenha na rede urbana colocam-na na condição de cidade média, articulando lugares em diferentes escalas. É preciso compreender Caruaru nas relações que se estabelecem.

A posição de Caruaru na rede pernambucana tem sido revalorizada pelo boom do consumo e pelas mudanças no perfil dos consumidores, explicado pela ampliação do seu papel regional gerado, sobretudo, pela ascensão das confecções e atividades correlatas. Não é possível falar dos processos urbanos em Caruaru sem tratar do setor de confecção, que tem recebido crescentes investimentos em 
ciência, inovação e tecnologia na última década, inclusive a partir da expansão do ensino superior. Nosso enfoque dar-se-á sobre a educação superior que, na nova divisão do trabalho, tem papel relevante na incorporação do conhecimento ao território e produção. Acreditamos que a sua oferta é fundamental na compreensão da rede urbana, sobretudo no contexto atual em que técnica, ciência e informação são elementos fundamentais para o desenvolvimento social e econômico de um lugar e de uma região.

No Brasil, nas últimas décadas, o Estado engendrou as bases para ampliação da educação superior para além das grandes cidades - por meio de políticas de expansão e criação de novas instituições, ampliação dos cursos e das vagas nas instituições públicas; bem como por programas de oferta de bolsas e financiamento estudantil nas instituições privadas -, provocando mudanças na urbanização das cidades receptoras, bem como ampliando e tornando mais complexas as interações espaciais interescalares. Há mais circulação de recursos financeiros, alteração na produção, expansão e consumo $\mathrm{da} /$ na cidade, ao permitir a convergência de um contingente populacional, com repercussão no consumo de bens e serviços. Assim, a tríade conhecimento-produção-consumo chama a atenção.

Nosso objetivo é discutir a condição de Caruaru na rede urbana, por meio das instituições de ensino. A hipótese é de que há uma alteração nos papéis e funções desempenhados por Caruaru e região a partir da expansão da educação superior nos anos 2000, bem como uma dinamização socioeconômica com a ampliação de suas interações espaciais. Analisamos um período recente da história de Caruaru e ainda em processo, em que o ensino superior deu uma guinada com a chegada de novas formas e novos conteúdos para atender às novas demandas do capitalismo.

Este trabalho insere-se numa pesquisa mais ampla financiada pela Coordenação de Aperfeiçoamento de Pessoal de Nível Superior (CAPES), "Grandes infraestruturas urbanas, ensino superior e desenvolvimento regional: reconfigurando as relações entre as 
cidades médias, as cidades pequenas e o campo", desenvolvida pela Rede de Pesquisadores sobre Cidades Médias - RECIME, em algumas cidades do Brasil.

\section{Caruaru e sua condição na rede urbana pernambucana}

O município de Caruaru está a 130 km da capital pernambucana, no Agreste. É cortado pelas BR-232 e BR-104 e tem a maior população do estado fora da Região Metropolitana do Recife-RMR (mapa 1). Elegemos Caruaru como recorte empírico para discutir, por meio da combinação entre suas singularidades e o contexto global de urbanização capitalista e a formação socioespacial brasileira, as particularidades das cidades médias, no que tange às mudanças/reforço em seus papéis e funções na rede urbana, pela educação superior.

Mapa 1 - Localização do Município de Caruaru -PE
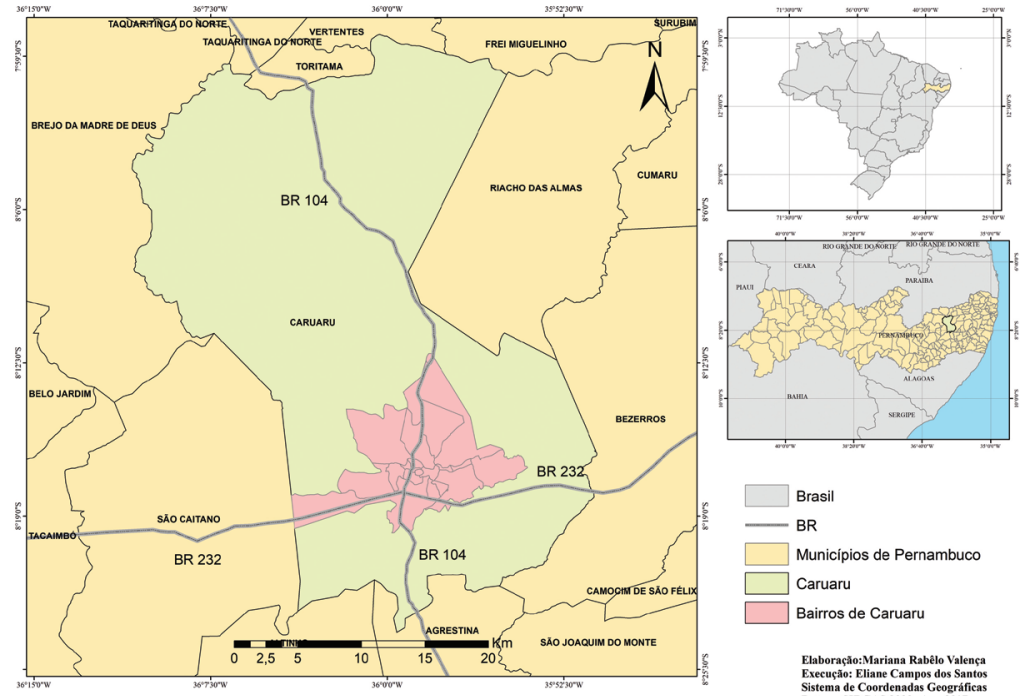
Sistemąa de Coordenadas Geogranficas Datum: SIRGAS 2000. Ano 20
Fonte de dados: IBGE 2015. 
Caruaru tem suas origens ligadas ao processo de interiorização da Capitania de Pernambuco, ainda no período colonial, com a doação de sesmarias divididas em fazendas de gado (Simonsen, 1977 apud Neves, 2003), cujo intuito era abastecer o Nordeste canavieiro. A primeira fazenda da região deu nome ao município e servia de apoio aos viajantes (IPHAN, 2014). Foram surgindo comércios de itens e serviços para gado. Mais tarde, a construção da capela Nossa Senhora da Conceição, em 1782, passou a ser atrativo religioso (Ferreira, 2001). Muitos aproveitavam a convergência de pessoas e traziam produtos agropecuários e outras mercadorias para trocas, que foi crescendo, diversificando-se (Ferreira, 2001), dando origem à feira, em 1818, e ao povoado de Caruaru.

Feira e povoado foram crescendo, numa relação simbiótica, atraindo cada vez mais gente do entorno em busca de determinados bens e para as atividades religiosas que aconteciam no local, estabelecendo, desde cedo, relações com outras escalas. Caruaru já exercia, naquele momento, funções comerciais e de serviços e religiosa. Em 1857, foi elevada à categoria de cidade, a primeira do Agreste pernambucano.

No final do século XIX, o ciclo do algodão chegou reverberando transformações territoriais (Condé, 2011), fazendo a cidade crescer mais do ponto de vista econômico e político. A instalação de uma Estação Ferroviária da Companhia inglesa Great Western, inaugurada em 1895, representou o "progresso" e a "modernidade", em direção ao semiárido pernambucano, e permitiu o escoamento da produção algodoeira. Nos anos 1920 e 1930, houve a decadência da economia algodoeira em Caruaru, atrelada à crise do capitalismo, à uma praga e à expansão da economia algodoeira paulista (Andrade, 2004). Outras atividades, ligadas ao setor agrícola, também enfrentaram uma crise, fazendo com que a força política do comércio crescesse ainda mais (Santos, 2006).

Entre os anos 1950 e 1980, Caruaru vivenciou transformações que refletiam mudanças pelas quais o Brasil passava, com a 
sua inserção no capitalismo industrial, articulado à urbanização e às mudanças demográficas (Silva, 2010). As mudanças pela qual Caruaru passava exigiam novas qualificações profissionais, fundamentais ao modo de vida urbano.

As condições de centralidade regional de Caruaru foram se articulando, principalmente, às atividades ligadas ao setor terciário, sobretudo àquelas que apresentavam certa complexidade, não encontradas nas cidades menores. Contudo, apesar de ter-se manifestado enquanto centralidade desde cedo, os processos mais recentes oriundos do contexto da reestruturação produtiva e da globalização reforçaram e ressignificaram seus papéis e funções.

Caruaru apresenta o quinto maior PIB do estado ( $\mathrm{R} \$ 6,2$ bilhões), ficando atrás de Recife, Jaboatão dos Guararapes, Ipojuca e Cabo de Santo Agostinho, todos da RMR (IBGE, 2010). Seu crescimento é superior ao de Pernambuco e do Brasil, como reflexo também do crescimento do número de empresas e de empregos formais (Caruaru, 2017).

Em termos demográficos (tabela 2), sempre se destacou no estado. De acordo com Cardoso (1965), em 1960 concentrava o maior contingente populacional do Agreste, devido ao fluxo migratório, constatando o seu papel polarizador. Em geral, os migrantes vinham de municípios próximos a Caruaru, em condições mais deficientes e estrutura agrária arcaica.

Tabela 2 - População do estado de Pernambuco, de Recife e de Caruaru - 1920-2017

\begin{tabular}{llll}
\hline Ano & Pernambuco & Recife & Caruaru \\
\hline 1920 & 2.154 .835 & 238.843 & 61.636 \\
\hline 1940 & 2.681 .032 & 348.424 & 73.455 \\
\hline 1950 & 3.395 .099 & 524.682 & 102.877 \\
\hline 1970 & 5.160 .640 & 1.060 .701 & 142.653 \\
\hline 1980 & 6.141 .993 & 1.203 .887 & 172.532 \\
\hline
\end{tabular}




\begin{tabular}{llll}
\hline 1991 & 7.127 .855 & 1.298 .229 & 212.938 \\
\hline 2000 & 7.918 .344 & 1.422 .905 & 252.987 \\
\hline 2010 & 8.796 .448 & 1.537 .704 & 314.912 \\
\hline 2017 & 9.473 .266 & 1.633 .697 & 356.128 \\
\hline
\end{tabular}

Fonte: IBGE - Censos Demográficos. Estimativa da População 2017. Organização: Mariana Valença.

De 1920 a 1970, Caruaru teve um aumento de 81.017 habitantes, o que representa o crescimento de mais de $130 \%$, enquanto Recife cresceu 344\% e Pernambuco, 139\%. Esses dados corroboram com o crescimento vertiginoso das metrópoles nesse período, em que Recife cresce demograficamente a passos mais largos que Caruaru, que está bem próximo ao crescimento do estado. No entanto, de 1970 a 2017, Caruaru cresceu 150\%, Recife, 54\% e Pernambuco, 84\%, confirmando a ideia de Santos (2009) de maior participação das cidades não metropolitanas no processo de urbanização brasileira. Essas mudanças no quadro populacional, tanto o seu aumento exponencial quanto na sua distribuição entre ambientes rurais e urbanos, refletem diretamente no crescimento da cidade, por meio da urbanização de espaços antes desocupados, aumentando as áreas construídas da cidade, as ruas e os bairros, e as necessidades de locomoção, bem como a demanda por serviços públicos. E o crescimento da população urbana em detrimento da rural altera hábitos, perfil econômico e de consumo, como o aumento do consumo de energia, muito maior em áreas urbanas.

Embora historicamente a cidade tenha desempenhado um papel de intermediação regional, articulando lugares, há um descompasso conceitual em tratar Caruaru como cidade média anteriormente à década de 1950, quando o termo foi adotado e passou a haver a preocupação com o estudo desse grupo de cidades na Europa e, no Brasil, nos anos 1970. 
O IBGE tem uma série de estudos sobre a rede urbana, que apresenta o conjunto de centros urbanos hierarquicamente organizados na condição de localidades centrais de Christaller, com suas respectivas áreas de influência, que possibilitam compreender as estruturas territoriais geradas pelos processos que ocorrem na sociedade e a tomada de decisão quanto à localização de investimentos em equipamentos e atividades econômicas de produção, consumo privado e coletivo. ${ }^{11}$

No primeiro estudo, Caruaru já era caracterizada como Centro regional de nível 2a, que estava ligado diretamente a centros de nível 1 , fazendo a intermediação entre Recife e o Sertão, e destacava-se na distribuição de bens e serviços e por sua atuação extra regional e comandando uma área com estruturação urbana definida, abrangendo centros de níveis inferiores (IBGE, 1972). Sua posição estratégica sempre atraiu um leque de atividades que lhe permitiram ser um importante entreposto comercial, econômico e cultural da região (Ferreira, 2002). Portanto, seu crescimento deu-se na articulação de um mercado regional.

No segundo estudo, realizado em 1978 e publicado em 1987, Regiões de Influência das Cidades (REGIC), Caruaru foi classificada como capital regional, por se situar numa condição imediatamente inferior à da metrópole regional.

No estudo de 1993, as cidades foram classificadas pelo nível de centralidade e Caruaru foi classificada com nível de centralidade muito forte, ampliando seu nível de centralidade e estabelecendo interações espaciais com um número bem maior de cidades tributárias.

No REGIC de 2007, Caruaru é classificada como uma Capital Regional C, uma cidade que se relaciona com os estratos superiores da hierarquia urbana, mas com nível de gestão inferior ao das

1 Há diferenças de caráter metodológico entre os estudos, ao adotar variáveis distintas, que interferiram nos resultados e na própria forma de classificação das cidades, de acordo com o próprio contexto histórico de cada momento da elaboração de cada estudo. 
metrópoles, e possui uma região de influência de 25 municípios no que diz respeito à oferta de um conjunto de atividades, no terceiro nível por ter porte menor e padrão de localização regionalizado (IBGE, 2008).

Em 2013, o IBGE lançou os resultados da Divisão Urbano-Regional, que integrou e correspondeu ao produto final do estudo de 2007. Esse estudo apresenta uma divisão regional por meio dos fluxos da rede urbana (IBGE, 2013). A divisão foi elaborada em três escalas de referência: Regiões Ampliadas de Articulação Urbana, Regiões Intermediárias de Articulação Urbana e Regiões Imediatas de Articulação Urbana. Recife comanda uma Região Ampliada de Articulação Urbana, que incorpora Caruaru e quase que a totalidade do estado de Pernambuco, devido à sua condição de metrópole regional, com peso no Nordeste. Já Caruaru, na condição de Capital Regional C, comanda uma Região Intermediária de Articulação Urbana, como uma subdivisão da escala anterior. Exerce uma centralidade mediana por concentrar bens e serviços de alta complexidade, atividades de gestão pública e privada, e articular órgãos e empresas privadas, em nível regional, polarizando muitos municípios (IBGE, 2013). A configuração dessa região é formada por 29 municípios. Já as Regiões Imediatas correspondem aos espaços vividos pelas populações e aos seus deslocamentos cotidianos, para ofertar ou buscar bens e serviços mais usuais (IBGE, 2013). A Região Imediata de Caruaru como subdivisão da Intermediária é composta por 23 municípios.

Em 2017, a partir do trabalho de 2013, o IBGE apresentou uma nova divisão regional do Brasil, substituindo as mesorregiões e as microrregiões por regiões intermediárias e regiões imediatas, respectivamente, incorporando as transformações ocorridas no Brasil nas últimas décadas, tendo nas questões relativas à rede e à hierarquia urbana seu elemento central.

As Regiões Geográficas Imediatas foram estruturadas a partir da centralidade urbana de algumas cidades quanto à oferta e 
ao consumo de determinados bens, serviços e atividades urbanas de caráter mais corriqueiro. As Regiões Geográficas Intermediárias articulam as Regiões Geográficas Imediatas por meio de um centro urbano de hierarquia superior de funções urbanas de maior complexidade, sendo delimitadas, de preferência, com a inclusão de metrópoles ou capitais regionais (IBGE, 2017). A Região Intermediária de Caruaru abrange as Regiões Geográficas Imediatas de Caruaru, Garanhuns, Arcoverde e Belo Jardim-Pesqueira, somando 66 municípios, que buscam bens e serviços mais complexos.

Caruaru hoje conta com importantes equipamentos urbanos para atender sua população e de sua região influência, como instituições de ensino, hospitais, centros de gestão pública, bancos e instituições financeiras, centros tecnológicos, unidades do "Sistema $S$ " (Sebrai, Sesi, Sesc, Senac e Senai). Sua localização, além de interferir na centralidade interna, pode interferir nas relações interurbanas, ampliando as possibilidades de deslocamento e de consumo (mapa 2). Além disso, há a produção de novas expressões de centralidade dentro da cidade, como o shopping center, o Polo Comercial, espaços que concentram atividades econômicas no espaço urbano e atraem um fluxo de pessoas. Seu espaço urbano, que era marcado pela presença de um único centro, começa a se transformar, com a instalação desses novos empreendimentos e equipamentos, tornando sua estrutura espacial mais complexa. 


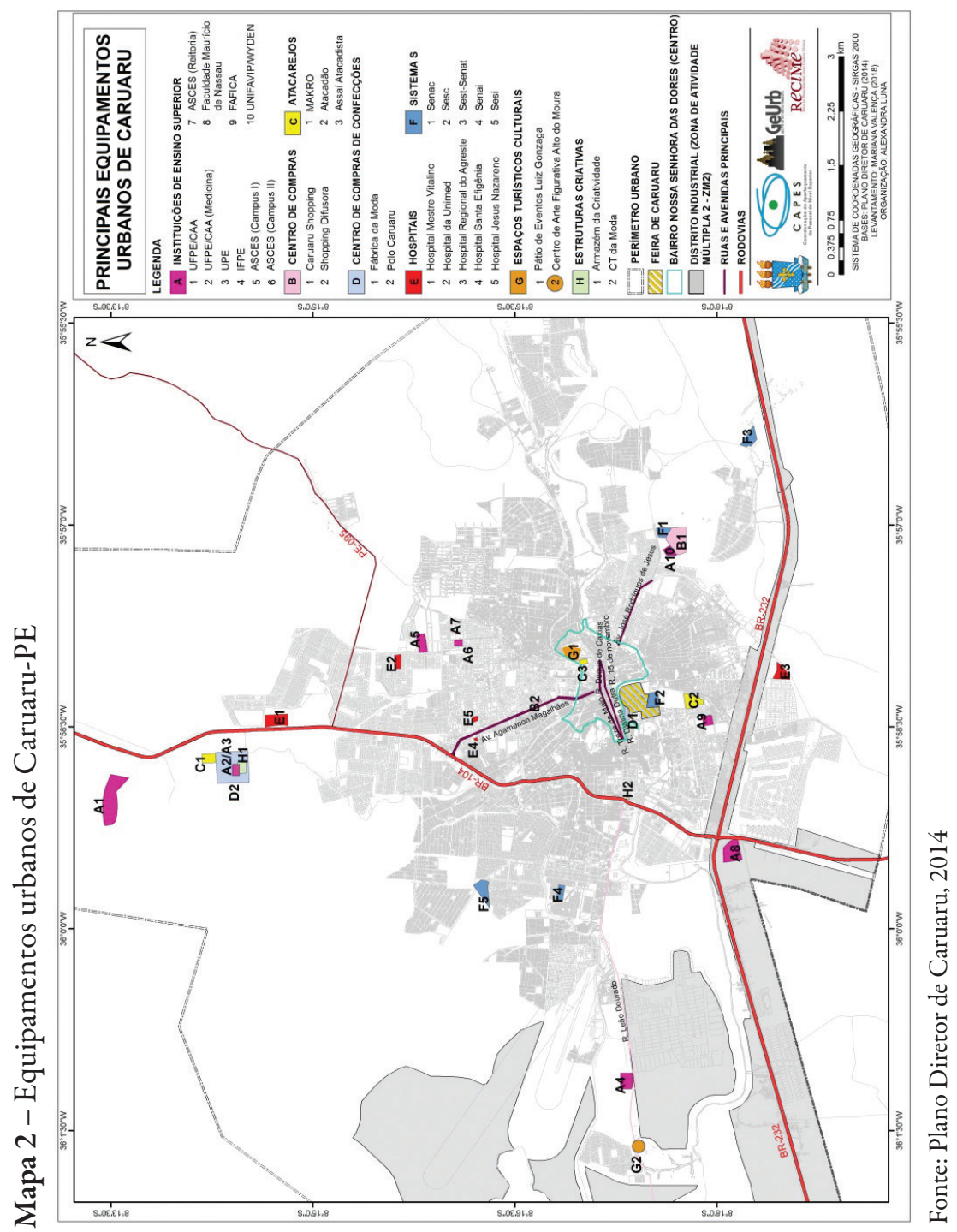


Essas questões contribuem para a reestruturação urbana e da cidade e ecoam as recentes tendências da produção capitalista do espaço das escalas estadual, nacional e até mesmo global, a partir das reestruturações produtivas, urbana, sem, contudo, deixar de apresentar as particularidades das cidades médias e as suas singularidades locais, interferindo na sua dinâmica econômica, social e política.

O boom do consumo revaloriza o lugar de Caruaru na rede urbana pernambucana. Isso diz respeito ao crescimento regional, gerado, sobretudo por meio da confecção e de atividades correlatas. Assim, não é possível falar de reestruturação urbana de Caruaru sem tratar desse setor, que já existe há algumas décadas, mas que tem recebido crescentes investimentos em inovação e tecnologia na última década, promovendo uma especialização produtiva da região, a partir de 2002, ao ser considerado pelo Ministério do Desenvolvimento, Indústria e Comércio Exterior (MDIC), Governo de Pernambuco e Instituto de Pesquisa Econômica Aplicada (IPEA) como Arranjo Produtivo Local (Xavier, 2018).

A política de promoção e apoio aos APL, fomentada pelo MDIC e com o envolvimento de vários organismos federais - inclusive o Ministério da Ciência e Tecnologia -, teve uma forte base territorial (Araújo, 2013), consistindo num amplo investimento em infraestrutura e equipamentos urbanos nessas áreas. O Estado de Pernambuco seguiu essa tendência e estabeleceu uma política de desenvolvimento regional a partir da criação de APL. Caruaru é o centro do APL de Confecções do Agreste, que contempla 20 municípios (mapa 3), entre eles, Santa Cruz do Capibaribe e Toritama, ${ }^{2}$ e contava, em 2012, com 3.831 empresas formais e 15.826 informais no ramo de confecções (SEBRAE-PE, 2013).

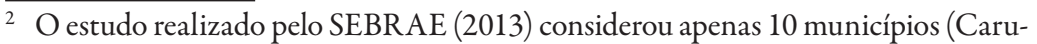
aru, Toritama, Santa Cruz do Capibaribe, Surubim, Cupira, Agrestina, Brejo da Madre de Deus, Riacho das Almas, Vertentes e Taquaritinga do Norte), embora reconhecesse outros quatro municípios com significativa atividade confeccionista (Belo Jardim, Gravatá, Passira e Pesqueira). Além disso, o estudo faz menção à tese 
Mapa 3 - Arranjo Produtivo Local de confecções do Agreste pernambucano

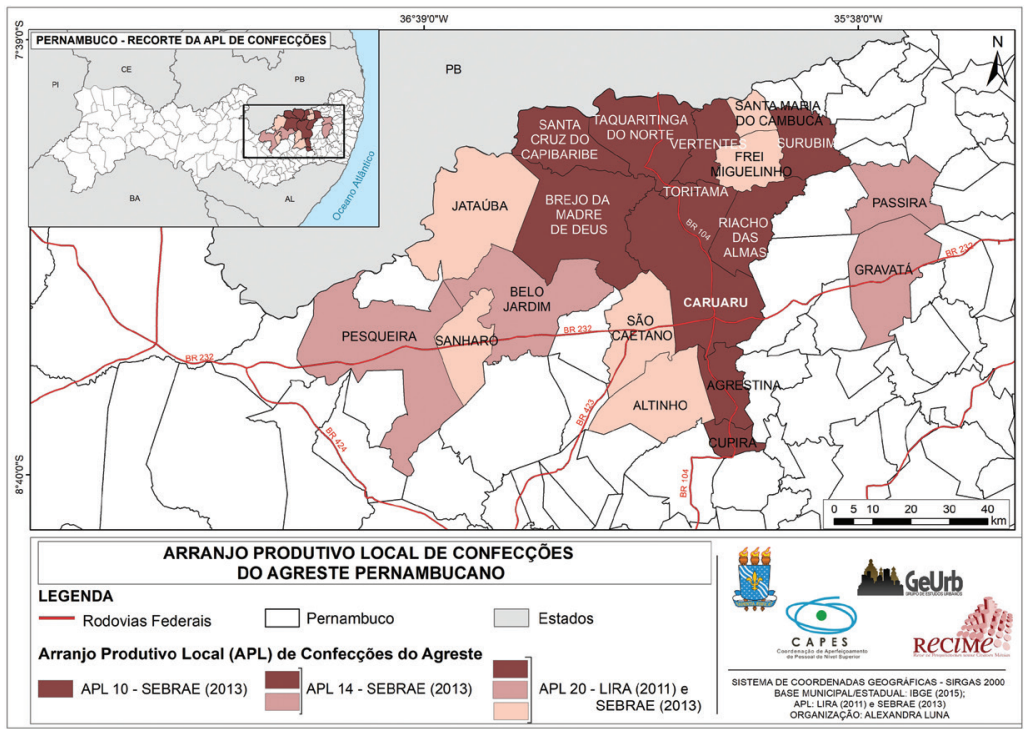

Fonte: IBGE, 2015

\section{De acordo com o ITEP,}

Arranjos Produtivos Locais (APL) são aglomerações de empresas localizadas em um mesmo território que apresentam especialização produtiva e mantêm algum vínculo de articulação, interação, cooperação e aprendizagem entre si e com outros atores locais tais como governo, associações empresariais, instituições de crédito, ensino e pesquisa. O objetivo principal de um Arranjo Produtivo Local é dinamizar as estruturas empresariais gerando renda e emprego.

Caruaru, Santa Cruz do Capibaribe e Toritama concentram as atividades do APL e são considerados os núcleos. Os três apre-

de doutorado em Geografia de Sônia Maria de Lira (2011), que enumera mais seis municípios: Altinho, Frei Miguelinho, Jataúba, Sanharó, Santa Maria do Cambucá e São Caetano. Mas o relatório reforçou sua escolha pelo aprofundamento em apenas dez municípios, porque estes concentram $95,5 \%$ das empresas formais e informais. 
sentaram crescimento significativo de sua população nas últimas décadas (tabela 3). A população de Caruaru teve uma variação de $18,7 \%$ de 1991 a 2000, enquanto que Toritama e Santa Cruz do Capibaribe, de 46,2\% e 54\%, respectivamente. Já no decênio seguinte, essa variação foi ainda maior para Caruaru, 24,2\%, e para Toritama, 63,1\%, enquanto Santa Cruz do Capibaribe teve uma variação inferior de 48,3\%, mas todos bem acima de Pernambuco, do Nordeste e do Brasil (SEBRAE, 2013).

Tabela 3 - Evolução da população dos três municípios centrais do APL

\begin{tabular}{lcccc}
\hline Municípios & $\begin{array}{c}\text { População em } \\
\mathbf{1 9 9 1}\end{array}$ & $\begin{array}{c}\text { População em } \\
\mathbf{2 0 0 0}\end{array}$ & $\begin{array}{c}\text { População em } \\
\mathbf{2 0 1 0}\end{array}$ & $\begin{array}{c}\text { População em } \\
\mathbf{2 0 1 7}\end{array}$ \\
\hline $\begin{array}{l}\text { Santa Cruz do } \\
\text { Capibaribe }\end{array}$ & 38.332 & 59.048 & 87.582 & 105.761 \\
\hline Toritama & 14.907 & 21.800 & 35.554 & 44.189 \\
\hline Caruaru & 212.938 & 252.987 & 314.912 & 356128 \\
\hline
\end{tabular}

Fonte: IBGE, Censo Demográfico 1991; IBGE, Estimativa da População 2017; BNDES, 2017 a e 2017b.

De acordo com SEBRAE (2013), esse crescimento demográfico, muito acima das médias estadual, regional e nacional, deu-se em decorrência do forte fluxo migratório em direção ao APL, em busca de oportunidades de emprego. Os dados de deslocamento pendular por motivos de trabalho reforçam essa questão (tabela 4).

Tabela 4 - Deslocamento pendular para trabalho (2010)

\begin{tabular}{lccc}
\hline Municípios & Ingressos & Egressos & Saldos \\
\hline Santa Cruz do Capibaribe & 2475 & 599 & 1876 \\
\hline Toritama & 2879 & 247 & 2632 \\
\hline Caruaru & 8535 & 2384 & 6151 \\
\hline
\end{tabular}

Fonte: IBGE, 2017. Organização: Xavier, 2018. 
Nesse contexto, insere-se a necessidade de incorporar ciência e tecnologia a produção como condição para reproduzir as condições de produção do arranjo produtivo, que articula diferentes interesses e proporciona novos mercados. A Secretaria de Ciência, Tecnologia e Inovação de Pernambuco (Secti), em parceria com o Instituto de Tecnologia de Pernambuco (ITEP), o SEBRAE e a Federação das Indústrias de Pernambuco (FIEPE), encabeça o Programa de Produção e Difusão de Inovações para a Competitividade de Arranjos Produtivos Locais (PROAPL), financiado pelo Banco Interamericano de Desenvolvimento (BID) (Xavier, 2018). Entram nesse cenário o Centro Tecnológico da Moda e o Armazém da Criatividade, estruturas de incentivo à inovação e ao empreendedorismo.

Com a expansão das atividades produtivas ou de suporte à confecção, os municípios que fazem parte do APL passaram por modificações estruturais nítidas na configuração espacial e na dinâmica socioeconômica (Xavier, 2018), alguns de modo mais intenso, outros de modo menos intenso. O crescimento acentuado do Produto Interno Bruto (PIB) dos três núcleos do APL, assim como a elevação do Índice de Desenvolvimento Humano Municipal nos dão uma dimensão do expressivo crescimento econômico e da melhoria de aspectos da vida social a partir da especialização produtiva na região (tabela 5).

Tabela 5 - PIB e IDHM dos três principais municípios do APL

\begin{tabular}{|c|c|c|c|c|}
\hline Municípios & PIB 1999 & PIB 2010 & $\begin{array}{c}\text { IDHM - } \\
2000\end{array}$ & $\begin{array}{c}\text { IDHM - } \\
2010\end{array}$ \\
\hline Caruaru & $\mathrm{R} \$ 736.887$ & $\begin{array}{c}\mathrm{R} \$ \\
3.872 .947 \\
\end{array}$ & 0,558 & 0,677 \\
\hline Santa Cruz do Capibaribe & $\mathrm{R} \$ 114.228$ & $\mathrm{R} \$ 766.084$ & 0,520 & 0,648 \\
\hline Toritama & $\mathrm{R} \$ 33.697$ & $\mathrm{R} \$ 387.474$ & 0,481 & 0,618 \\
\hline
\end{tabular}

Fonte: IBGE, 2015. Organização: Twane Xavier, 2018. 
Fica evidente que o processo de urbanização regional tem relação com a ampliação do setor produtivo de confecções. Embora seu peso não seja tão grande em Caruaru, por sua diversidade econômica, a cidade, na condição de intermediária, atrai recursos e investimentos, por meio de equipamentos e infraestruturas. A própria educação superior, como lugar da formação profissional e do desenvolvimento de ciência e tecnologia, entra nesse quesito.

\section{Instituições de Ensino Superior e estruturas de suporte ao empreendedorismo e a inovação em Caruaru}

$\mathrm{Na}$ atualidade, a ciência, a técnica e a informação passam a engendrar o processo de produção do espaço. Dessa forma, busca-se incorporar ciência e tecnologia ao território mediante ações que vinculem instituições de ensino superior, de pesquisa e de apoio à inovação e ao empreendedorismo com os setores produtivos locais e regionais.

Para Santos e Silveira (2000), o território brasileiro cria necessidades de qualificação/formação de pessoas nos lugares, impondo sua lógica ao desenvolvimento do ensino e mais ainda do ensino superior. Ao longo do tempo, com uma maior difusão do meio técnico-científico-informacional pelo território brasileiro, vê-se uma crescente demanda por novas áreas de conhecimento e a oferta de educação superior passa a se diversificar para atender as exigências desse movimento. Existe, portanto, no período recente, uma grande demanda por educação, que implica um crescimento expressivo do número de matrículas nas graduações presenciais e do número de instituições de ensino superior pelo território brasileiro. Há também uma expansão dos cursos de pós-graduação, visto que a maior parte do desenvolvimento científico e tecnológico ancora-se nesse nível (Vieira, 2017).

No início do século XXI, a expansão da educação superior brasileira é marcada por alterações na configuração espacial, tendo sua interiorização intensificada a partir de políticas públicas e dos programas federais, como o Programa de Apoio a Planos de Reestruturação 
e Expansão das Universidades Federais (Reuni), o Programa Universidade para Todos (ProUni), Fundo de Financiamento Estudantil (Fies), Sistema de Seleção Unificada (SiSU), ampliando o número de vagas tanto em instituições públicas, quanto nas privadas. Estas últimas têm recebido incentivos governamentais, por meio do ProUni e do FIES, permitindo o acesso de uma população mais carente ao ensino privado. A atuação de grupos empresariais vinculados ao capital financeiro na educação, em certa medida, tem a anuência do Estado.

As mudanças nos padrões locacionais também se relacionam às mudanças relativas à reestruturação urbana, em que cidades de estratos inferiores da rede urbana também passam a receber equipamentos e infraestruturas antes concentradas nas grandes cidades. Assim, naquelas regiões mais distantes dos grandes centros metropolitanos, deu-se início a uma série de processos - construções de novos campi, concursos públicos para contratação de professores e funcionários, aumento da oferta do número de vagas para estudantes, ampliação da diversidade de cursos oferecidos. Esses novos campi movimentam as economias locais, atraindo novos moradores, que criam demandas nos setores de habitação, comércio e serviços.

Nesse caso, as cidades médias, pelo papel que exercem, acabam sendo privilegiadas, com rápida repercussão na vida cultural e alterações na dinâmica econômica e no papel desempenhado enquanto centralidades regionais pautadas em serviços. A presença dessas instituições amplia as possibilidades produtivas para a economia local - sem deixar de contribuir para o desenvolvimento regional, pois há, com sua presença, a dinamização econômica devido à alteração do consumo citadino (Soares, 2010).

O período técnico-científico-informacional requer um novo papel das IES, agora capazes de articular atores, agentes e escalas geográficas, mediando interesses e mobilizando recursos, para desenvolver estratégias com repercussões positivas no desenvolvimento social e econômico e com mudanças na produção do espaço urbano. Nesse sentido, as IES não são elementos apenas de uma política educacional, 
mas de uma política regional, a partir da incorporação de conhecimento ao território por meio de interações espaciais interescalares.

Em Caruaru, a educação superior chegou por meio da instalação do Centro Universitário Tabosa de Almeida ASCES - UNITA (antes apenas Associação Caruaruense de Ensino Superior), pioneiro, no final dos anos 1950, no processo de interiorização da oferta de ensino superior no Norte-Nordeste, para atender a uma demanda da sociedade local. Durante 43 anos, a instituição só funcionou com dois cursos: Odontologia e Direito.

Logo em seguida, em 1960, a Faculdade de Filosofia, Ciências e Letras de Caruaru também foi fundada, pela Diocese de Caruaru, oferecendo alguns cursos voltados, principalmente, à formação de professores. É provável que, naquele momento, o governo federal não tivesse um planejamento para ampliação e interiorização do ensino superior, mas aproveitou os interesses dos grupos que solicitavam autorização para funcionar e facilitou o andamento do processo (Ferreira, 2002). Para Ferreira (2002), o Governo transferiu, de forma premeditada, naquele momento, a responsabilidade do ensino superior para a iniciativa privada, atendendo às pressões da sociedade e de grupos econômicos. Durante muitos anos, apenas essas duas instituições atendiam à demanda da região e tinham um peso relevante para o desenvolvimento social e econômico. Para além disso, era necessário deslocar-se para a capital pernambucana em busca de instituições públicas e de um leque maior de cursos.

A terceira IES, também privada, só foi instalada em Caruaru em 2001. Depois disso, mais cinco instituições foram instaladas, sendo duas privadas e três públicas. O período recente é marcado por uma nova temporalidade que demonstra como a política federal de escala nacional reforça a centralidade local-regional.

É importante pensar o novo contexto em que a universidade desempenha um papel importante no processo produtivo e na inovação da produção, contribuindo para o desenvolvimento de "Sistema Produtivo e Inovativo Local”, por meio da qualificação profissional e da 
produção de conhecimento e de tecnologia, de acordo com as necessidades que emergem das atividades do arranjo produtivo (Firmino, 2014).

Atualmente, em Caruaru, funcionam sete IES na modalidade presencial, que oferecem centenas de possibilidades de cursos superiores (nos graus bacharelado, licenciatura e tecnólogo). Há também uma expansão da oferta de cursos técnicos e profissionalizantes.

A Universidade de Pernambuco (UPE) já havia disposto, há cerca de cinco décadas, de três campi fora da região metropolitana. Em 2006, Caruaru recebeu uma unidade. No âmbito federal, no mesmo ano, a Universidade Federal de Pernambuco (UFPE) também foi inaugurada; e, em 2010, o Instituto Federal de Educação Ciência e Tecnologia de Pernambuco (IFPE). Estas duas últimas instituições contaram com recursos financeiros do Reuni, embora o Campus Acadêmico do Agreste da UFPE tenha sido instalado antes da implantação do programa, em parceria com os governos estadual e municipal.

Para a escolha da cidade de Caruaru para a instalação da UFPE foi considerada:

[... sua relevância no contexto atual da região do Agreste, que possui como principais características: cadeias e arranjos produtivos predominantes nas áreas da confecção e da agroindústria, e principal centro de serviços e negócios e de distribuição de mercadorias. O CAA vem suprir a necessidade de ensino gratuito e de qualidade na região, visto que há cursos superiores já instalados, em sua maioria oferecidos por instituições privadas (CAA, 2007).

Em 2014, a Faculdade Maurício de Nassau (FMN) começou a funcionar também no local, por meio da ampliação da UNINASSAU - Centro Universitário Maurício de Nassau que já se faz presente em várias cidades, sobretudo, do Nordeste. A cidade foi escolhida por sua localização central na região, bem como por se apresentar como polo de educação superior. 
No quadro do ensino superior de Caruaru, há a presença de cursos voltados à especialidade produtiva da região - antes só encontrados na capital, como Engenharia Mecânica, Engenharia de Produção, Design, Moda -, assim como muitos cursos voltados para a realização da vida cotidiana, para a ampliação da oferta de serviços à população da cidade e da região. A natureza, quantidade e qualidade dos cursos ofertados respondem a divisão social do trabalho e aprofundam-na, ao passo que a escolha de um curso é "uma opção social, econômica, política, cultural e territorialmente condicionada", resultante da demanda por um saber e de uma reivindicação social (Santos e Silveira, 2000, p. 60).

Ademais, fica evidente que, mesmo no caso das IES privadas, o Estado, por meio das políticas públicas voltadas ao ensino superior, destaca-se como principal agente. São novas formas com novos conteúdos e uma nova dinâmica conferida às velhas formas.

Além disso, durante os governos do Partido dos Trabalhadores, buscou-se superar a ausência de tradição do sistema brasileiro de Ciência, Tecnologia e Inovação, partindo da premissa de que não se alcança desenvolvimento econômico e bem-estar social sem investir nesses setores, fundamentais para a posição do país no mercado internacional (Rezende, 2013). Para Fernandes (2006), é importante fortalecer um sistema territorial de produção de conhecimento e inovação, voltado ao desenvolvimento regional, a partir de agentes econômicos locais, mais comprometidos com o lugar do que os que atuam em escalas mais amplas. Sem isso, a estrutura socioeconômica fica mais susceptível aos interesses externos.

Caruaru apresenta duas estruturas inovativas, que são uma resposta à necessidade abordada por Rezende (2013) e por Fernandes (2016): o Centro Tecnológico da Moda (CT Moda) e o Armazém da Criatividade, ligados ao Instituto Tecnológico de Pernambuco e ao Porto Digital, respectivamente. Ambas beneficiam, pincipalmente, empreendedores do setor de confecções. As estruturas foram instaladas em Caruaru, por sua centralidade regio- 
nal e pela presença de IES, mas atendem o APL como um todo e trabalham de modo integrado às instituições de ensino, ciência e tecnologia e aos setores econômicos.

No contexto da globalização, as políticas devem fortalecer as regiões, sobretudo as que ficaram por muito tempo relegadas ao atraso, para que cada região seja a solução dos seus próprios problemas. Essas instituições são ferramentas desse tipo de política que promovem a diminuição das desigualdades regionais, ampliando a capacidade tecnológica local e regional. Assim, as estruturas inovativas fortalecem as horizontalidades ao reforçarem a solidariedade territorial, na medida em que viabilizam um aporte inovativo e tecnológico para espaços que se viam distantes geográfica e economicamente. Portanto, assim como as IES, são elementos fundamentais para o desenvolvimento regional e contribuem para a ampliação de uma massa crítica e para a conquista de novos mercados, em novas escalas, ainda que tornem o espaço mais competitivo, capaz de receber empresas com estratégias globais.

\section{Produção, expansão e consumo na/da cidade-região}

As interações espaciais articulam lugares por meio do deslocamento/fluxo material e imaterial. Nesse caso, pensamos o ensino superior em Caruaru como elemento que liga outros espaços a esta cidade, por meio do deslocamento de alunos, professores e funcionários de outros municípios. E é por meio desses deslocamentos que pessoas de áreas antes desprovidas de determinados bens e serviços passam a se conectar ao mundo.

Nos anos de 2016 e 2017, realizamos pesquisa de campo em que foi possível fazer o levantamento das cidades de origem de todos os estudantes matriculados em cinco IES, que permitiu verificar a centralidade exercida por cada uma das instituições. Embora as pesquisas tenham sido realizadas em períodos diferentes, revelam desigualdades espaciais, uma vez que os deslocamentos dão-se, em geral, a partir de locais com baixa densidade de atividades. 
Ao todo, das faculdades ASCES/UNITA, FAFICA, Unifavip/Wyden, UFPE e UPE, ${ }^{33}$ contabilizamos 19.473 alunos matriculados no ensino superior. É interessante notar que 11.743 são oriundos de outros municípios de Pernambuco, além dos 220 que vêm de outros estados, ou seja, os estudantes de fora representam mais da metade dos estudantes. Portanto, é inegável o papel das IES na centralidade caruaruense.

Foram aplicados, ainda, 444 questionários com os estudantes das IES presenciais de Caruaru, exceto a FMN, que não autorizou a realização da nossa pesquisa, dos quais 285 foram aplicados com pessoas do sexo feminino e 159 do sexo masculino. Os cursos foram escolhidos junto à gestão de cada IES, buscando abranger diferentes áreas do conhecimento.

$\mathrm{Na}$ Unifavip, foram aplicados 161 questionários com estudantes, sendo 38 de Direito, 20 de Farmácia, 52 de Arquitetura e Urbanismo, 19 de Engenharia Civil, 20 de Nutrição e 12 de Enfermagem. Na FAFICA, foram 46 questionários, 15 em Letras, 15 em Administração e 16 em Análise e Desenvolvimento de Sistema. Na ASCES, 35 de Direito, 30 de Odontologia e oito de Licenciatura em Educação Física. No IFPE, foi aplicado no seu único curso de graduação, Engenharia Mecânica, com 14 estudantes. Na UFPE, foram 42 alunos de Pedagogia, 43 de Administração e 24 de Medicina. Na UPE, foram 34 de Administração e sete de Sistema da Informação.

É notória as transformações espaciais devido à expansão do ensino superior. A doação de terra para a construção das IES, seja pelo poder público para atender a uma demanda social, seja por proprietários particulares para valorização da terra, contribui para a expansão da mancha urbana. Além disso, a localização das IES na cidade também são relevante no que diz respeito aos processos urbanos. Todas

3 A FMN, como já dito outrora, não nos forneceu esse tipo de informação; e o IFPE forneceu dados de todo campi, incluindo os alunos dos cursos técnicos de nível médio, que não é do nosso interesse. 
as IES públicas funcionam na periferia da cidade, contribuindo para uma maior circulação de pessoas nessas áreas (mapa 4).

Mapa 4 - Distribuição espacial das instituições de ensino superior presenciais no zoneamento urbano do Plano Diretor de Caruaru

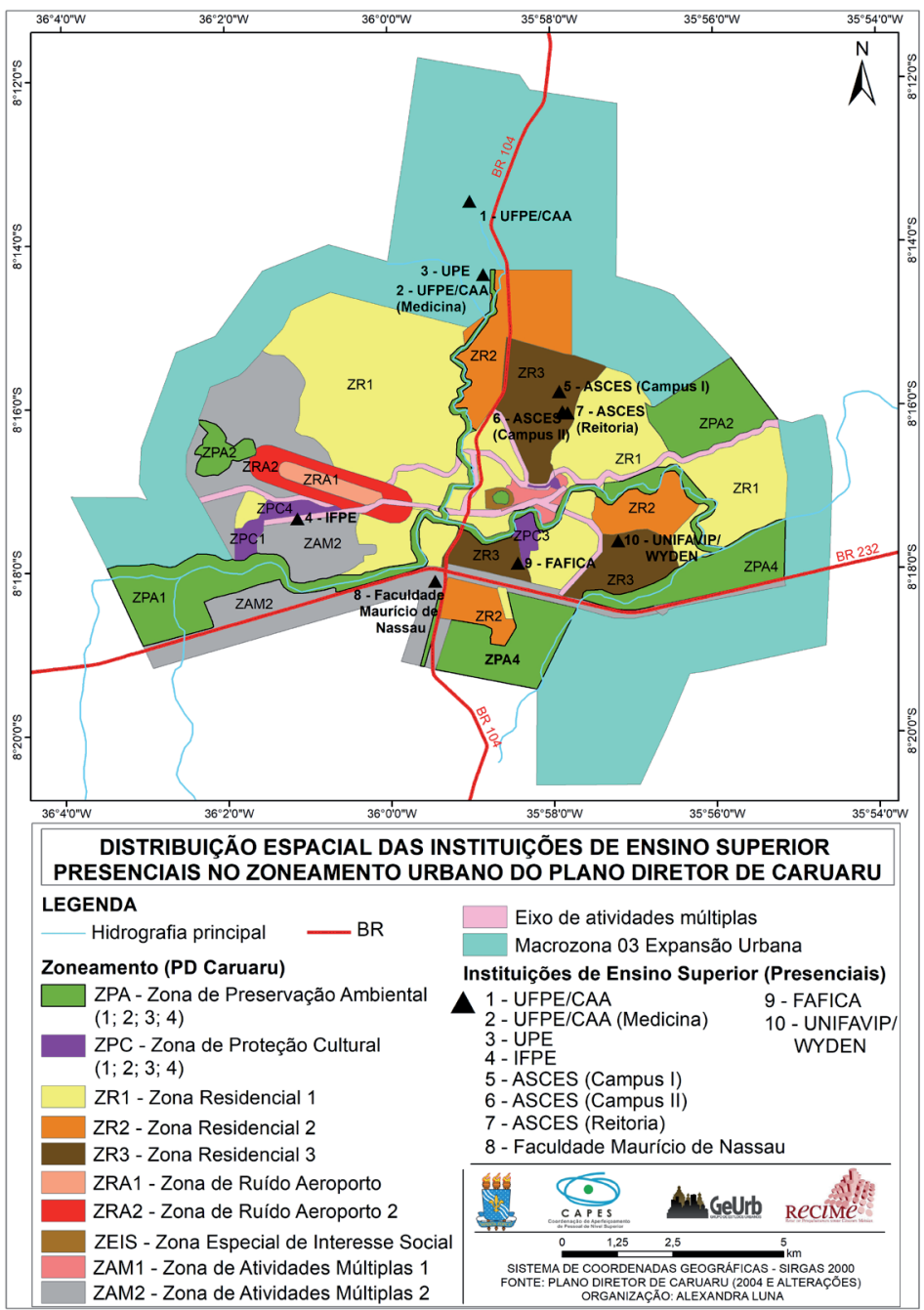

Fonte: Plano Diretor de Caruaru, 2014 e alterações. 
ASCES, FAFICA e Unifavip, de acordo com o Plano Diretor-PD de 2004 (Caruaru, 2004), situam-se na Zona Residencial 3, que corresponde a parte dos bairros do Maurício de Nassau, Petrópolis, Universitário e Indianópolis e seu uso é predominantemente habitacional unifamiliar e multifamiliar. No PD, já se apontava a tendência à ocupação e à verticalização, em razão da presença de equipamentos urbanos. Além disso, a área onde se localiza a Unifavip/Wyden, no bairro de Indianópolis, tem passado por profundas transformações, em virtude da instalação do Caruaru Shopping, em 1999, da própria IES, em 2001, e, mais recentemente, em 2015, do WA Hotel Caruaru. É notório o crescimento das construções no entorno desses empreendimentos e a valorização imobiliária da área, inclusive ao lado do shopping, onde há um grande empreendimento imobiliário.

A UPE, no Polo Caruaru, e a UFPE estão dentro da área correspondente à ampliação da Macrozona 03 de Expansão Urbana, pela Lei Complementar 008/2006. São áreas que estão no limite do perímetro urbano e que têm recebido grandes equipamentos urbanos, como o Polo Caruaru, o Alphaville Caruaru, o Hospital Mestre Vitalino, o Makro e a Universidade Federal de Pernambuco, fazendo com que haja uma intensificação da ocupação dessa área.

A Maurício de Nassau e o IFPE estão na Zona de Atividades Múltiplas 2, que tem uso majoritariamente industrial e de comércio atacadista e serviços, compreendendo os distritos industriais e a área de expansão em seu entorno, ao norte do Aeroporto e ao sul da BR-232.

A implantação e a localização das IES mais recentes reforçam a estrutura urbana pré-existente, ao mesmo tempo em que, contribuem para organização interurbana/reforço de centralidade, ao instalarem-se em áreas de expansão urbana e nas proximidades dos principais eixos viários que ligam Caruaru a sua região.

A Unifavip/Wyden, que está interligada ao Caruaru Shopping, e a UPE e a UFPE (Medicina), que funcionam dentro do Polo Caruaru, contribuem para a atração de consumidores para os 
centros de compras e serviços, favorecendo a reprodução do capital, criando áreas no interior do espaço urbano com expressóes de centralidade.

Nota-se também a valorização de áreas pelo mercado imobiliário, evidenciada por sua estrutura, nos bairros Universitário e Indianópolis. A demanda por moradia, para atender aos estudantes e professores que passam a estabelecer moradia na cidade, certamente interfere nesse processo. Há também uma reestruturação do espaço interno da cidade com a chegada de estudantes do ensino superior. Há uma valorização de determinadas áreas, em função da demanda por moradia e por outros serviços essenciais e por comércio.

O espaço urbano de Caruaru vai se conformando como uma mancha urbana descontínua, de bordas indefinidas e vazios urbanos com a ocupação de áreas afastadas das já consolidadas, penalizando, sobretudo, as camadas mais pobres da sociedade com a locação de empreendimentos habitacionais populares cada vez mais distantes, cuja viabilidade econômica configura-se também pela distância das áreas centrais, dificultando a mobilidade e $\mathrm{o}$ acesso a bens e serviços (Oliveira, 2016). As Leis que ampliaram o perímetro urbano já previam determinados equipamentos urbanos, inclusive a instalação da UFPE.

Aos poucos, há uma mudança na dinâmica intraurbana, exigindo investimentos em serviços coletivos e em equipamentos urbanos, pouco presentes nessas áreas. Além disso, no atual contexto social em que há uma maior demanda por qualificação profissional, a educação superior incorpora-se às diversas atividades produtivas.

Os números da pesquisa revelam, e isso fica nítido nos mapas, que a centralidade de Caruaru no que diz respeito ao serviço de educação superior vai além da sua região imediata. Os municípios que mais enviam estudantes para cursar o ensino superior em Caruaru estão dentro da sua região intermediária, mas, no total, foram identificados 154 municípios do estado de Pernambuco (mapa 5), além dos municípios de outros estados. 
Mapa 5 - Municípios de origens dos estudantes do ensino superior em Caruaru 2016 - 2017

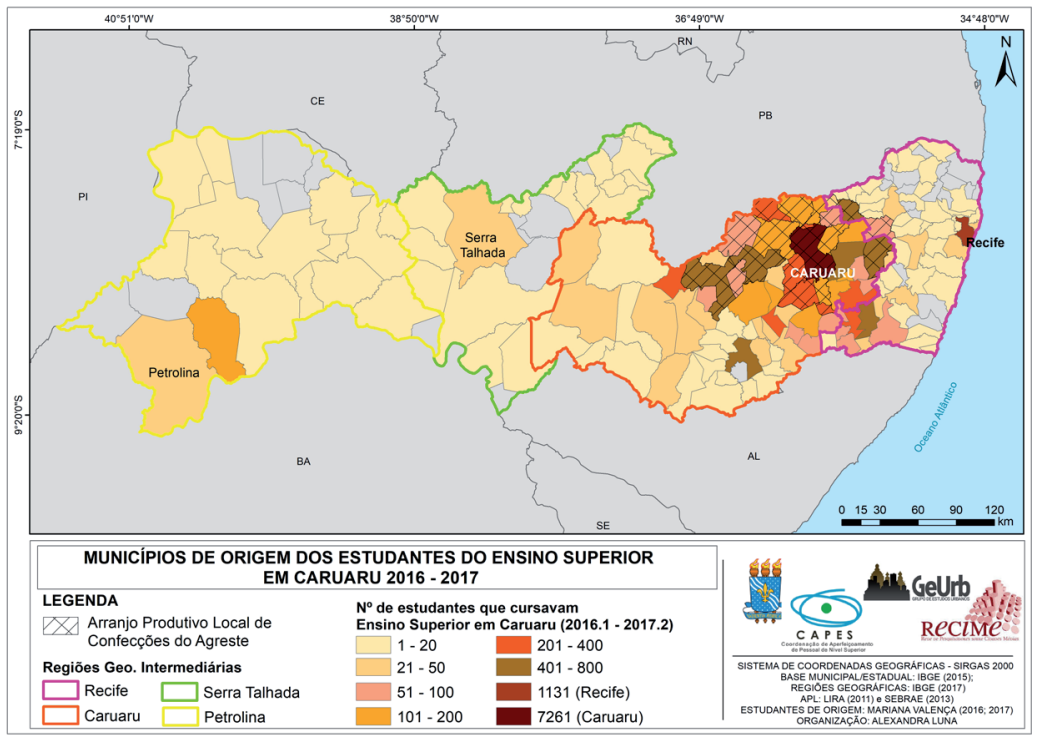

Fonte: IBGE, 2015/2017

Além disso, os municípios do APL de Confecções, considerando o APL 20, estão entre os com maior número de estudantes do ensino superior de Caruaru, como Belo Jardim (763), Toritama (366), Santa Cruz do Capibaribe (395), Pesqueira (408). O enriquecimento pela confecção contribui para uma ampliação do consumo, inclusive de serviços mais complexos, como o ensino superior. O crescimento regional explica os novos padrões de consumo.

O deslocamento de pessoas para estudar em Caruaru revela as diferenças que existem entre os lugares. De um lado, Caruaru, concentrando fixos que estabelecem relações com seu entorno; de outro, diferentes lugares com uma baixa densidade técnico-científica que precisam recorrer a outros espaços para viabilizar sua reprodução socioespacial.

Esses deslocamentos têm um custo e são, portanto, seletivos. Há uma clivagem econômica de acordo com os cursos e com os 
custos para se deslocar e/ou manter-se na cidade. Essa centralidade é seletiva, assim como o tipo de curso e de IES são seletivos. Quem tem acesso é quem pode acessar essa centralidade. Há assim centralidades diferentes. Além disso, esses deslocamentos resultam de uma totalidade, das condições produtivas e da ação do Estado, fazendo com que os lugares relacionem-se por meio de seu aparato técnico. Portanto, podem ser vistos como interação, lugar da ação e da troca, em que a sociedade articula-se entre si aos diversos lugares, que, nas suas singularidades, articulam-se a espaços globais.

Ademais, a oferta do serviço especializado de educação superior (privada) localizado numa cidade média para uma região dá-se numa relação de horizontalidade, mas que, no entanto, pode ser controlada por agentes econômicos externos (Sobarzo, 2008), numa relação de verticalidade. Em Caruaru, há a presença de instituições que atuam por meio de lógicas definidas pelas interações com o capital de abrangência nacional e internacional, como é o caso da Unifavip/Wyden e da Faculdade Maurício de Nassau. Há relações entre lógicas, agentes e empresas que atuam em múltiplas escalas e que contribuem tanto para fortalecer a especialização produtiva quanto para diversificar a produção regional. A articulação de agentes e os arranjos político-institucionais constituem espaços seletivos, como um meio e um produto de estratégias político-econômicas. Geram-se processos de reescalonamento em Caruaru, por meio de seus potenciais produtivos, técnicos e políticos.

Desse modo, acreditamos ser possível falar de reestruturação urbana e reestruturação da cidade a partir do Ensino Superior, na medida em que esse reflete ao mesmo tempo em que interfere no crescimento econômico regional, alterando os papéis e as funções urbanas de Caruaru e de toda sua região, além das transformações internas ocasionadas pela expansão da educação superior. 


\section{Caruaru: uma cidade de responsabilidade territorial?}

A região de Caruaru é marcada pelo setor de confecções em que se manifestam desigualdades socioeconômicas e territoriais. $\mathrm{O}$ ensino superior tem papel crucial não apenas para o crescimento econômico e para o fortalecimento e especialização do arranjo produtivo, mas também social, inclusive minimizando as desigualdades.

Para Santos e Silveira (2000), bens e serviços de interesse geral, como a educação, quando não têm uma oferta pública universal, são disponibilizados pelo setor privado, de acordo com interesses e decisões políticas. O setor privado segue a lógica do mercado, é orientado pela demanda solvente, ao passo que cabe ao setor público equilibrar essas questões, ofertando educação superior em áreas menos favorecidas social e economicamente. No entanto, há uma lógica de mercado que orienta e que também está introjetada nas IES públicas, na medida em que existe uma disputa por matrículas para garantir verbas, que são destinadas de acordo com a produtividade das instituições. E, ainda, como já foi dito anteriormente, a política de educação superior na escala nacional, que beneficiou diferentes estratos da rede urbana e regiôes anteriormente desprivilegiadas, também estava articulada a outras políticas setoriais; entre elas, a política de ciência, tecnologia e inovação e a política que promoveu os APL. Sendo assim, há um viés econômico muito forte presente na política de educação superior. Contudo, ainda assim é preciso reconhecer o caráter social desse processo.

Como boa parte dos alunos vem de outros municípios, sobretudo da Região Intermediária de Caruaru, contribui para uma maior articulação e fortalecimento regional, por meio da dinamização econômica com incorporação de ciência, tecnologia e inovação a produção. Além disso, a qualificação de pessoas altera o quadro socioeconômico dos municípios emissores de estudantes. Muitos são os primeiros da família a cursarem o ensino superior. Há uma maior integração socioterritorial intensificada pela educação. 
Há o aumento da produção, expansão e consumo da cidade/ região, alavancada pelo crescimento econômico. Entretanto, queremos enfatizar a ampliação da dimensão humana, seguida de uma ampliação do exercício da cidadania, por meio do acesso a determinados serviços, antes inacessíveis para grande parcela da população. Assim, mesmo que haja uma lógica do capital guiando este processo, tem-se o estabelecimento de interações espaciais dentro da região, que a refuncionalizam dentro de um quadro socioeconômico na rede urbana, redefinindo a centralidade de Caruaru com uma dimensão mais cívica, pautada nas horizontalidades, embora, voltamos a repetir, esse não seja o interesse do capital.

Para Trindade Jr. e Madeira (2016), isso ajuda a pensar em territórios menos corporativos, voltados a uma ordem territorial cuja cidadania é vetor da estruturação de objetos e ações que dão sentido à dinâmica espacial, de encontro aos modelos que reforçam assimetrias territoriais, pautadas em verticalidades. É possível pensar em novas geografias do desenvolvimento a partir de um modelo cívico de ordenamento territorial, conforme apontado por Santos (2007), que colocam a cidade como o locus do exercício pleno da cidadania.

Como no período técnico-científico-informacional, as cidades médias são importantes nós da rede, articulando múltiplas escalas ao permitir intermediação entre o local e o global, sendo assim importante elo de estruturação do território regional. Enquanto encruzilhada de horizontalidades e verticalidades, as cidades médias, no contexto atual, ampliam as interações espaciais interescalares, que agora são também heterárquicas. Essas cidades possibilitam acesso a bens e serviços mais sofisticados, pela centralidade que exercem.

Desse modo, ao apresentarem alternativas ao entorno, com "a implantação de equipamentos e infraestrutura urbana de natureza socioeconômica e voltados à modernização territorial, que possibilita o acesso a pessoas antes privadas, pela distância espacial e econômica, dos municípios vizinhos" com impacto no território, essas cidades apresentam uma "responsabilidade territorial" (Bitoun, 2009). 
A cidade de Caruaru, com o seu leque de comércio e serviços, é historicamente importante nó de articulação regional. Com o ensino superior, a cidade tem seus papéis e funções ampliados, por meio de uma política setorial do Estado nacional de caráter regional, mediante mudanças e permanências em sua história recente, com importantes repercussões socioeconômicas no território regional.

\section{Considerações finais}

Caruaru tem peso econômico e demográfico dentro de Pernambuco e conta com importantes equipamentos urbanos para atender não apenas à sua população, mas também de toda a sua região influência. Seu processo atual de urbanização tem relação com a ampliação do setor produtivo de confecções e de atividades correlatas. Como cidade intermediária, Caruaru atrai equipamentos e infraestruturas de suporte às atividades do Arranjo Produtivo Local de Confecções do Agreste, a exemplo do ensino superior e de estruturas inovativas.

A expansão do ensino superior em cidades médias atende às novas exigências econômicas de incorporação de ciência e tecnologia ao território e a produção. Nesse sentido, a presença de IES é um importante vetor na dinâmica socioespacial não apenas no que diz respeito às mudanças de ordem física, mas que possibilitam o desenvolvimento regional, por meio da oferta de conhecimento e cultura à sociedade. Nesse contexto, as cidades médias passam a ter uma importância ainda maior na articulação de escalas dentro da rede urbana. Os papéis e as funções de Caruaru só são regionais e reforçados nessa extensão escalar porque há uma tendência à constituição da dimensão regional que se constrói no momento em que Caruaru extrapola as interaçóes territoriais regionais para as interações espaciais, atingindo as escalas nacional e global descontinuamente, portanto, com vistas às articulações que são reforçadas pelos agentes atuantes na produção desta cidade. Vai se constituindo um 
território produtor de conhecimento e de suporte à inovação, a partir da instalação e ampliação das IES, além das estruturas inovativas por sua condição de intermediação na rede urbana.

Em Caruaru, nota-se a presença de cursos voltados à especialidade produtiva. E grande parte dos estudantes vem da Região Intermediária de Caruaru, mais ainda, dos municípios da região enriquecidos recentemente pela confecção. O boom no consumo, inclusive do serviço de educação, pode ser explicado pelo crescimento regional do APL.

Nesse sentido, o ensino superior, associado a outras questões territoriais, vem contribuindo para o processo de reestruturação urbana, a partir das novas possibilidades de interações espaciais interescalares, embora sejam mudanças muito recentes que ainda estão em curso em termos de reestruturação econômica da cidade e da região.

As IES, associadas às estruturas inovativas, permitem que Caruaru e região articulem-se com escalas mais amplas inserindo-as no seio da globalização. Mas entendemos que a constituição de um território agora também marcado, ainda que de modo incipiente, pela ciência, tecnologia e inovação fortalece, mais ainda, as horizontalidades e a solidariedade no território regional, ao permitir um aporte inovativo e tecnológico para espaços que se viam distantes geográfica e economicamente. Portanto, as IES são vetores fundamentais para o desenvolvimento regional que fazem de Caruaru uma cidade de "responsabilidade territorial", podendo, dessa forma, ajudar a pensar o ordenamento territorial de modo menos corporativo e mais cívico, na medida em que ampliam o exercício da cidadania. 


\section{Referências}

ANDRADE, M. C. DE. A terra e o homem no Nordeste: contribuições ao estudo da questão agrária no Nordeste. 7. ed. São Paulo: Cortez, 2004.

ARAÚJO, T. B. "Desenvolvimento regional brasileiro e políticas públicas federais no governo Lula”. In SADER, E. (org.). 10 anos de governos pós-neoliberais no Brasil: Lula e Dilma. São Paulo: Boitempo; Rio de Janeiro: FLACSO Brasil, 2013.

BITOUN, J. “Tipologia das cidades brasileiras e políticas territoriais: pistas para reflexão”. In BITOUN, J. e MIRANDA, L. (Orgs.). Desenvolvimento e cidades no Brasil: contribuições para o debate sobre as políticas territoriais. Recife: FASE, 2009. pp. 17-44.

BNDES. Informações socioeconômicas municipais. Caruaru. Pernambuco. 2017a.

Informações socioeconômicas municipais. Santa Cruz do Capibaribe. Pernambuco. 2017b.

CAA. Campus acadêmico do agreste. Disponível em: http://www.ufpe.br/caa/ index.php?option $=$ com_content\&view $=$ article\&id $=55 \&$ Itemid $=71$. Acesso em: 13 jul. 2015.

CARDOSO, M. F. T. C. "Caruaru: a cidade e sua área de influência”. In: Revista Brasileira de Geografia. out.-dez. 1965.

CARUARU. Lei complementar no 005 de 27 de julho de 2004: Plano Diretor de Caruaru. 2004

. Lei complementar n. ${ }^{\circ}$ 007, de 05 de setembro de 2006. 2006a.

. Lei complementar n. ${ }^{\circ}$ 008, de 13 de novembro de 2006. 2006b.

. Lei complementar n. ${ }^{\circ}$ 022, de 02 de setembro de 2010. 2010.

.SECRETARIA DE DESENVOLVIMENTO ECONÔMICO E ECO-

NOMIA CRIATIVA. Nota técnica 01/2017. 24 fev. 2017.

CONDÉ, J. Terra de Caruaru. 6. ed. Caruaru: W. D. Porto da Silva, 2011. 
FERNANDES, A. C. "Sistema territorial de inovação ou uma dimensão de análise na Geografia contemporânea”. In SPOSITO, E. S. et. al. (orgs.). A diversidade da Geografia brasileira: escalas e dimensões de análise e da ação. Rio de Janeiro: Consequência, 2016.

FERREIRA, J. E. "Caruaru nos anos 60: aspectos histórico-econômicos e educacionais". In CALADO, A. J. F. (org.). Educação e Protagonismo: relatos e análises de experiências do cotidiano escolar. João Pessoa: Ideia Editora Ltda, 2002, pp. 43-58.

FERREIRA, J. E. Ocupação humana do Agreste pernambucano: uma abordagem antropológica para a história de Caruaru. Caruaru: Ideia, 2001.

FIRMINO, A. L. DA S. A interiorização das universidades federais e os arranjos produtivos locais : o caso da Unidade Acadêmica de Garanhuns (UAG/UFRPE). (Dissertação). Recife: Universidade Federal Rural de Pernambuco, 2014.

IBGE - INSTITUTO BRASILEIRO DE GEOGRAFIA E ESTATÍSTICA. Divisão do Brasil em regióes funcionais urbanas. Rio de Janeiro: IBGE, 1972.

. Divisão regional do Brasil em regiões geográficas imediatas e regiões geográficas intermediárias . Rio de Janeiro : IBGE, 2017.

. Divisão Urbano-Regional. Rio de Janeiro: IBGE, 2013

. Regiões de Influências das Cidades - 1993. Rio de Janeiro: IBGE, 1993.

. Regiões de Influências das Cidades - 1978. Rio de Janeiro: IBGE, 1987.

. Regiões de Influências das Cidades - 2007. Rio de Janeiro: IBGE, 2008.

. Séries Históricas. s.d.

. Enciclopédia dos municípios brasileiros. v. XVIII. Rio de Janeiro: IBGE, 1958.

. Censo Demográfico 1920. Rio de Janeiro: IBGE, 1920.

. Censo Demográfico 1940. Rio de Janeiro: IBGE, 1940.

. Censo Demográfico 1950. Rio de Janeiro: IBGE, 1950.

. Censo Demográfico 1970. Rio de Janeiro: IBGE, 1970. 
. Censo Demográfico 1980. Rio de Janeiro: IBGE, 1980.

. Censo Demográfico 1991. Rio de Janeiro: IBGE, 1991.

. Censo Demográfico 2000. Rio de Janeiro: IBGE, 2000.

. Censo Demográfico 2010. Rio de Janeiro: IBGE, 2010.

IPHAN. Feira de Caruaru, patrimônio cultural brasileiro. 2014. Disponível em: http://portal.iphan.gov.br/uploads/ckfinder/arquivos/Feira\%20de\%20 Caruaru.pdf. Acesso em: 2 fev. 2016.

ITEP. CT DA MODA. Disponível em: www.itep.br/ct-moda-caruaru.

LIRA, S. M. "Os aglomerados de micro e pequenas indústrias de confecções do agreste/PE: um espaço construído na luta pela sobrevivência". Revista de Geografia da UFPE, Recife, n. 23, v. 1, pp. 98-114, 2006.

NEVES, A. L. Estudo morfológico de cidades do agreste pernambucano - século XVIII e XIX. (Dissertação). Pernambuco: UFPE, 2003

OLIVEIRA, A. G. Crescimento urbano versus urbanidade: estudos sintáticos da espacialidade de Caruaru-PE. (Dissertação). Recife: UFPE, 2016

REZENDE, S. M. "Uma década de avanço em ciência, tecnologia e inovação no Brasil”. In SADER, E. (org.). 10 anos de governos pós-neoliberais no Brasil: Lula e Dilma. São Paulo: Boitempo; Rio de Janeiro: FLACSO Brasil, 2013

SANTOS, M. O espaço do cidadão. 7. ed. São Paulo: Editora da Universidade de São Paulo, 2007.

. A urbanização brasileira. São Paulo: Edusp, 2009.

e SILVEIRA, M. L. O ensino superior público e particular e o território brasileiro. Brasília: ABMES, 2000. 163 p.

SANTOS, V. J. Falas da cidade. Um estudo sobre as estratégias discursivas que constituíram historicamente a cidade de Caruaru-PE (1950-1970). (Dissertação). Recife: Universidade Federal de Pernambuco, 2006.

SEBRAE-PE. Estudo Econômico do Arranjo Produtivo Local de Confecções do Agreste Pernambucano, 2012. Recife: SEBRAE, 2013. 
SILVA, J. D. "Algodão: O “Ouro Branco" de Caruaru e do Nordeste”. In: Jornal Vanguarda. 03 jul. 2010. Disponível em: http://www.jornalvanguarda.com. $\mathrm{br} / \mathrm{v} 2 /$ ? pagina $=$ noticias\&id $=6368$. Acesso em: 2 out. 2016 .

SOARES, B. R. et. al. "Uberlândia (MG): leituras geográficas de uma cidade média em transição”. In: ELIAS, D. et. al. Agentes econômicos e reestruturação urbana e regional: Tandil e Uberlândia. São Paulo: Expressão Popular, 2010.

SOBARZO, O. "As cidades médias e a urbanização contemporânea". Cidades, v. 5, n.8, 2008.

TRINDADE JR., S.C. C. e MADEIRA, W. V. "Polos, eixos e zonas: cidades e ordenamento territorial na Amazônia”. In: PRACS: Revista Eletrônica de Humanidades do Curso de Ciências Sociais da UNIFAP. Macapá, v. 9, n. 1, p. 37-54, jan./jun. 2016. Disponível em: https://periodicos.unifap.br/index. php/pracs ISSN 1984-4352.

VIEIRA, D. J. "Evolução do ensino superior brasileiro em período recente: novas perspectivas para o desenvolvimento regional?” In: MONTEIRO NETO, A; CASTRO, C. N. DE, e BRANDÃO, C. A. Desenvolvimento Regional no Brasil - Políticas, estratégias e perspectivas. Rio de Janeiro: IPEA, 2017.

XAVIER, T. Transformações urbanas no Polo de Confecções do Agreste de Pernambuco: um olhar sobre Santa Cruz do Capibaribe. (Dissertação). Recife: UFPE, 2018. 